\title{
Knowledge, Attitude and practice towards condom utilization among patients enrolled on antiretroviral therapy: Case of Mokoni health centre, Northern Ethiopia
}

\author{
KidaneTadesse $^{1, *}$, Samson Weldegebriel ${ }^{2}$, Fekadu Fentabil ${ }^{2}$, Habtamu Endashaw ${ }^{2}$, Liqu Mogos $^{2}$, \\ Meseret Teferi ${ }^{2}$ \\ ${ }^{1}$ Mekelle University, College of health Sciences, Department of Public Health, Biostatistics and Health Informatics, Mekelle, Ethiopia \\ ${ }^{2}$ Mekelle University, College of health Sciences, School of Medicine, Mekelle, Ethiopia
}

\section{Email address:}

Kiducs98@yahoo.com (K. Tadesse)

\section{To cite this article:}

KidaneTadesse, Samson Weldegebriel, Fekadu Fentabil, Habtamu Endashaw, Liqu Mogos, Meseret Teferi. Knowledge, Attitude and Practice towards Condom Utilization among Patients Enrolled on Antiretroviral Therapy: Case of Mokoni Health Centre, Northern Ethiopia. Science Journal of Public Health. Vol. 2, No. 5, 2014, pp. 502-506. doi: 10.11648/j.sjph.20140205.29

\begin{abstract}
The burden of HIV/AIDS high in sub-Saharan countries which constitutes two third of globe and is worst in Ethiopia. Therefore identifying determinants of consistent condom use in HIV patients who are on ART had paramount importance in the prevention and control of the diseases. A little is known about the practice of condom use among HIV positive patients. The aimed of this study was to assess knowledge, attitude and practice towards condom utilization among people living with HIV/AIDS enrolled on ART in Mokoni town. An institutional based cross sectional study was conducted among ART users in Mokoni health center from June-august 2013. Data on the study variables was gathered using semistructured questionnaire. After the subject was asked for their volunteer participation, then we collected data using interview. Descriptive statistics was used to determine the frequency and percentage of different variables. Data was presented in the form of tables and graphs. From the total study participants 177(56.73\%) were females. Among 312 participants $35(11.22 \%)$ of them had knowledge about people on ARV can't transmit the HIV virus to un infected partners ,277(88.73\%) knew even people taking ARV can transmit HIV to un infected partner .From the total 312 respondents 136(43.59\%) had attitudes about people on ARV tend to engage in risky sexual practice ,176(56.41\%) didn't believe people on ARV tend to engage in risky sexual practice. among the total respondents 121(38.78\%) agreed that because of availability of ARV people could again engage in un protected sex, 64(20.51) agreed that it was safe to engage in unprotected sex with a person taking ARV. From 165 who were currently use Patterns of condom use among 165 who are using condom currently and $116(70.30 \%)$ were consistently used a condom. The majority of patients ART enrolled always use a condom during sexual intercourse. Significant numbers of the respondents were well confident about using condoms and attended session demonstrating about using condoms. Free and explicit discussion on safe sex and enhanced positive attitudes toward condom use should be encouraged.
\end{abstract}

Keywords: KAP, HIV, ART, Ethiopia

\section{Background}

Human Immune deficiency Virus (HIV) infection is a serious public health problem. According to estimates from the World Health Organization (WHO), there are more than 36 million people are infected and 22 million had already died, and another 3.5 million became newly infected with HIV. Though the production of Antiretroviral Therapy (ART) started since 1990; it was universally recognized that access to HIV/AIDS treatment and care till recently was highly inequitable (1). Globally every day 6800 persons became infected with HIV and over 5700 persons die from AIDS because of inadequate access to HIV prevention and treatment services (2).

The burden of HIV/AIDS is high in sub -Saharan countries which constitutes two third of the globe and is worst in Ethiopia. As strategy for prevention, condom use practice among others the most effective method against HIV infection. Therefore, identifying determinants of 
consistent condom use in HIV patients who are on ART had paramount importance in the prevention and control of the disease (3).The risk of HIV transmission is dependent on individual ability to adhere to the medical regimen which affects both development of resistance to treatment drug and viral load. Additional crucial behavioral determinants of sexual transmission include inconsistent condom use, especially in combination with concurrent sexual partner (4).

AIDS has killed more than 25 million people since it was first recognized in 1981. Globally an estimated 39.5 million people were living with $\mathrm{HIV}$ and close to 4.3 million people were newly infected with the virus (5).

Sub-Saharan region bears $68 \%$ of global HIV burden. Reports on sexual behaviors of people on ART have been inconsistent; six studies in African and non African countries have shown that patients on ART are more likely engage in unprotected sex, however, other cross-sectional and longitudinal studies have reported a decrease in rate of risk sexual behavior after ART(6).

A growing number of HIV infected Ethiopians have gained access to ART so that by 2010; 246,347 Ethiopians in need of treatment were receiving ART. In Ethiopia it remains much to be done to understand why, when and what conditions people living with HIV/AIDS (PLWHA) practice risky sexual behavior. A little is known about the practice of condom use among HIV positive patients. Until recently the focus of HIV prevention efforts in most country including Ethiopia was largely on people uninfected with HIV and the sexual risky practice of HIV infected person didn`t receive any serious attention(7). This study is, therefore, to assess the knowledge, attitude and practice of condom utilization on ART enrolled patients in Mokoni health center.

\section{Methods and Materials}

\subsection{Study Design and Setting}

An institutional based cross-sectional study was conducted among all PLWHA who are enrolled on ART in Mokoni health center. This study was conducted in Mokoni health center which is found in Mokoni town, southern zone of Tigray regional state at a distance of $661 \mathrm{~km}$ and $122 \mathrm{~km}$ from Addis Ababa and Mekelle respectively. The town has one health center, three private drug venders and three private clinics which provide health services to the community. In the health center there are 1110 ART enrolled patients. There are also 1084 pre-ART patients.

\subsection{Population and Sampling}

The study population includes all ART enrolled patients of the Mokoni health center, out of which 312 were included in this study. The sample size was calculated using single population proportion formula, with the assumptions $\mathrm{P}=$ prevalence of condom among sexually active respondents who are ART experienced $(\mathrm{p}=47.4 \%), \mathrm{d}=$ margin of error $(5 \%), 95 \%$ CI. The study participants were selected using systematic random sampling from the total ART enrolled patients in Mokoni health center. The sampling interval was, $R=1110 / 312=4$, so that the first participant was selected randomly from the first four ART enrolled patients then every 4th participant was chosen until sample size attained.

\subsection{Ethical Consideration}

Ethical clearance was obtained from Mekelle University, college of health sciences. Permission also was asked from Mokoni health bureau and official letter was written and sent to Mokoni health center. The confidentiality and privacy of respondents was maintained by all data collectors. The willingness and non response right of participants was respected.

\section{Results}

\subsection{Socio-Demographic Characteristics}

Table 1. Socio- demographic characteristics of ART enrolled patients in Mokoni, Northern Ethiopia, 2013.

\begin{tabular}{|c|c|c|}
\hline Variables & Frequency & Percentage $(\%)$ \\
\hline \multicolumn{3}{|l|}{ Age } \\
\hline $15-24$ & 55 & 17.7 \\
\hline $25-34$ & 114 & 36.6 \\
\hline $35-44$ & 104 & 33.4 \\
\hline$>=54$ & 39 & 12.3 \\
\hline \multicolumn{3}{|l|}{ Sex } \\
\hline Male & 135 & 43.3 \\
\hline Female & 177 & 56.7 \\
\hline \multicolumn{3}{|l|}{ Religion } \\
\hline Orthodox & 249 & 79.8 \\
\hline Muslim & 63 & 20.2 \\
\hline \multicolumn{3}{|l|}{ Educational status } \\
\hline Illiterate & 205 & 65.7 \\
\hline Primary & 81 & 26 \\
\hline Secondary & 21 & 6.7 \\
\hline college level and above & 5 & 1.6 \\
\hline \multicolumn{3}{|l|}{ Occupational status } \\
\hline Farmer & 148 & 47.4 \\
\hline Merchant & 44 & 14.1 \\
\hline Government employee & 13 & 4.2 \\
\hline Private employee & 25 & 8 \\
\hline House wife & 17 & 5.5 \\
\hline Daily labourer & 26 & 8.3 \\
\hline Student & 9 & 2.8 \\
\hline Jobless & 17 & 5.5 \\
\hline Commercial sex worker & 13 & 4.2 \\
\hline \multicolumn{3}{|l|}{ Marital status } \\
\hline Married & 155 & 49.7 \\
\hline Single & 50 & 16 \\
\hline Divorced & 71 & 22.8 \\
\hline Widowed & 36 & 11.5 \\
\hline
\end{tabular}

A total of 312 people living with HIV enrolled in ART responded to the questionnaire making the response rate of 
$100 \%$. From the total study participants $135(43.27 \%)$ were males and $177(56.73 \%)$ of them were females. Among the study participants majority of them were in the age interval of 25 -34 and 35-44 that makes each about 63(20.19\%).out of the total of 312 respondents $249(79.81 \%)$ were orthodox and $63(20.19 \%)$ of them were Muslim

Of the total ART enrolled patients participated in this study, 205(65.70\%) were illiterate, $81(25.96 \%)$ were primary level of education, $21(6.73 \%)$ were secondary and the rest 5(five) were college level and above .among 312 respondents $148(47.44 \%$ ) were farmers, $44(14.13 \%)$ were merchants, 13 were governmental employee, 25 were private employee, 17 were house wife, 26 were daily laborers, 9 were students, 17 were jobless and 13 were commercial sex workers in their occupational status. From the total 312 study subjects $155(49.68 \%$ ) were married, $50(16.08 \%)$ were single, $71(22.75 \%)$ were divorced and $36(11.54 \%)$ were widowed. Detail description of sociodemographic characteristics is shown below table1.

\subsection{Knowledge About HIV Transmission and Condom Utilization}

Table 2. Respondents' knowledge on HIV transmission in Mokoni among patients enrolled on ART, Northern Ethiopia, 2013

\begin{tabular}{|c|c|c|c|c|}
\hline \multirow{2}{*}{ Item } & \multicolumn{2}{|l|}{ Yes } & \multicolumn{2}{|l|}{ No } \\
\hline & Frequency & $\%$ & frequency & $\%$ \\
\hline HIV can be transmitted through unprotected sex with HIV/AIDS taking ARVs & 303 & 97.12 & 9 & 2.88 \\
\hline Unprotected sex with infected partner taking ARVs could result in contracting HIV & 286 & 91.8 & 26 & 8.33 \\
\hline $\begin{array}{l}\text { People on ARVs less likely to transmitting HIV to their sexual partner during sexual } \\
\text { intercourse }\end{array}$ & 166 & 53.20 & 146 & 46.80 \\
\hline
\end{tabular}

Table 3. Sources where ART enrolled patients get condoms in Mokoni, Northern Ethiopia, 2013.

\begin{tabular}{lll}
\hline Source & Frequency & Percentage \\
\hline Health center & 256 & 83.66 \\
Pharmacy & 4 & 1.30 \\
Shops & 14 & 4.57 \\
Health center and pharmacy & 12 & 3.92 \\
Health center , pharmacy and shop & 8 & 2.61 \\
Health center and shop & 2 & 0.65 \\
Hotels & 10 & 3.26 \\
\hline
\end{tabular}

Of the total 312 participants 303(91.12\%) knew HIV can be transmitted through un protected sex with HIV/AIDS infected partner not taking ARV .but 9 of them didn't knew. Among 312 respondents 286(91.67\%) had knowledge about unprotected sex with infected partners as contracting HIV even taking ARV, the rest 26(8.33\%) hadn't knowledge about it. Only 166(53.20\%) knew people on ART less likely transmitting HIV to their sexual partners during sexual intercourse, whereas the rest 146 (46.80\%) knew even though people on ART transmit HIV to their sexual partners during sexual intercourse as people who are not ART .

Among 312 participants $35(11.22 \%)$ of them had knowledge about people on ARV can't transmit the HIV virus to uninfected partners, 277(88.73\%) knew even people taking ARV can transmit HIV to uninfected partner.

From a total of 312 study subjects who responds to questions that are related to condom knowledge 312(100\%) knew condom. 306(98.10\%) knew as condom prevent HIV, 301(96.47\%) knew condom prevent STI ,306(98.10\%) knew condom prevent pregnancy and 305(97.70\%) knew condom reduce chance of HIV infection. all respondents knew condom couldn't be reused .out of the total respondents 274(87.82\%)knew HIV can't pass through a condom, $38(12.18 \%)$ responded that HIV can pass through a condom.

\subsection{Attitude towards Condom Utilization}

From the total 312 respondents 136(43.59\%) had attitudes about people on ARV tend to engage in risky sexual practice ,176(56.41\%) didn't believe people on ARV tend to engage in risky sexual practice. among the total respondents $121(38.78 \%)$ agreed that because of availability of ARV people could again engage in un protected sex, 64(20.51) agreed that it was safe to engage in unprotected sex with a person taking ARV .from the total 312 respondents $275(88.14 \%$ ) agreed people of their town accepted condoms. $268(85.89 \%)$ of the respondents talked to their sexual partner about condom use. among the total respondents $180(57.69 \%)$ agreed that sexual intercourse with condom as good as without a condom, the rest didn't agree . $147(47.12 \%)$ disagreed condom use reduce sexual pleasure, the rest $165(52.88 \%)$ responded that condom use can reduce sexual pleasure.

\subsection{Practice towards Condom Utilization}

Out of 312 participants $208(66.70 \%)$ had sexual partner, but $104(33.30 \%)$ hadn't sexual partner, among those who had sexual partner $174(83.60 \%)$ had only single sexual partner ,5 (five) had two sexual partner , 7(seven) had three 
sexual partner and 22 had 4 ( four ) and above sexual partners. among 208 people who had sexual partner , 72 $(34.6 \%)$ had sexual relation with their wife , 84(40.38\%) with their husband ,17 with commercial sex workers and 22 with their friends as sexual partner. From a total of 312 respondents 223(71.47\%) had ever used a condom .and $89(28.53 \%)$ hadn't ever used a condom. out of 223 who had ever used a condom $165(73.99 \%)$ were currently used a condom .but $58(26.01 \%)$ didn't use a condom currently. From 58 who didn't currently used a condom, 22(37.93) were because of being uninterested, seven were due to religious reason, $22(37.93 \%)$ were due to hadn't partner and 7 were due to need of children.

Out of 312 respondents $306(98 \%)$ could able get a condom if they need but 6 of them couldn't able to get a condom if they need .from those 306 who could able get a condom if need, 256(83.60\%) of them were get a condom from health center, 4 of them from private pharmacy 14 from shops, 12 from health center and pharmacy, 8 from health center, shops and pharmacy, 2 from health center and shops and 10 of them get from hotels.

Out of 312 respondents 306(98\%) thought that condom supply was enough but 6 were not and all of them respondent thought that as the cost was fair. 249(79.8\%) were confident about how to use a condom but $63(20.19 \%)$ weren't, and 250(80.12\%) had ever attend in session demonstrating using a condom. from 165 who were currently use Patterns of condom use among 165 who are using condom currently d a condom 116(70.3\%) were consistently used a condom the rest 49(29.69\%) were not used a condom consistently .

\section{Discussion}

In our study about $91.12 \%$ knew HIV can be transmitted through unprotected sex with HIV/AIDS infected partners not taking ART, $91.67 \%$ had knowledge about un protected sex with infected partner contracting HIV, even taking ART. This is consistent with study done in Uganda that was $86.3 \%$ and $94 \%$ respectively (10). This study finding showed that $100 \%$ of the respondents knew condom prevent HIV. This is higher than compared with a study done in South Africa which was $85 \%$ (11). This discrepancy might be due to health education about condom utilization. In this study 96.5\% knew condom prevents STI, 98.1\% had knowledge condom prevents pregnancy, and $97.76 \%$ knew condom reduce chance of HIV infection. This is comparable with a study done in Uganda, that was $97.7 \%, 100 \%$ and $97 \%$ respectively(10).

This study findings showed that $38.78 \%$ respondents agreed because of availability of ART people could again engaged in unprotected sex, which is higher than a study conducted in Addis Ababa which was $23 \%$ (7). This difference could be due to in our study $65.7 \%$ were illiterate .This study revealed that $43.59 \%$ of them tend to engage in a risky sexual practice which was much higher than a study conducted in South Africa which was $19 \%$ (11). This might be due to high numbers of respondents were illiterate. In this study $85.9 \%$ respondent could talk to their sexual partner about condom use, 52.9\% agreed condom use reduce sexual pleasure. This is consistent with a study conducted in Uganda which was $84 \%$ and $50 \%$ respectively (10).

In this study $83.6 \%$ of participants had only one sexual partner and $16.4 \%$ had multiple sexual partners. This study is almost similar with the study done in Addis Ababa that was about $90 \%$ and $10 \%$ respectively. Regarding with whom had sexual intercourse $75 \%$ with their regular sexual partner, 5\% with commercial sex workers ,8\% with non regular sexual partner. This study finding is almost comparable with study done in Felege Hiwot hospital that was $88.5 \%, 5.1 \%$ and $6.4 \%$ respectively (14). This study finding showed that $71.47 \%$ had ever used a condom. This is much higher than a study conducted in Nigeria $38 \%$ (9). This might be due to active and well integrated health information dissemination and service in the health center where we conducted the study. Only $12 \%$ of these who didn't use a condom currently were due to religious reason.This was higher than the study conducted in South Africa which was $4 \%$ (11). About $12 \%$ were because of need of having child which is much lower than the study conducted in Addis Ababa public hospitals that was 24.3\% (13). In this study $98 \%$ of participants could get condom if they need. This finding is higher than a study conducted in Addis Ababa public hospital which was 87\% (13). This study finding showed that $79.8 \%$ were confident about how to use a condom. This is similar with a study conducted in Uganda (79.1\%) (10). regarding attending in session demonstrating using condom about $80.12 \%$ have attended. This is much higher than study conducted in Uganda which was $57.4 \%$ (10). This might be due to good coordinating health package and link group's integration with support group.

This study revealed that the majority of ART enrolled patients were females, illiterate, farmers and high number of divorced and widowed. Almost all of the respondents were knew condom. The majority of patients ART enrolled always use a condom during sexual intercourse Respondents are convinced of safety and effectiveness of condoms as prevention tool against HIV, STI and pregnancy. There is positive perception to condom use by patients on ART. There is enough supply of condoms in the health center which is given to each patient with kit aid. Significant number of participants knew that HIV can be transmitted through unprotected sex with HIV infected partners not taking ART and taking ART. Majority of respondents used a condom currently and consistently. Significant number of the respondents was well confident about using condoms and attended session demonstrating about using condoms. 


\section{References}

[1] Awel M. Anti Retroviral treatment adherence and its determinants among people living with HIV/AIDS on Highly Active Anti Retroviral Therapy in two Hospital of Oromiya regional state,Ethiopia. In:Legesse B,Seyoum D, and Lakew Y(eds). Extracts from EPHA-sponsored Master`s Theses in HIV/AIDS.Addis Ababa,Ethiopa: Ethiopian Public Health Association(EPHA),extract no 4,2008:10.

[2] Kfilie A. Disclosure among currently partnered HIV positive individuals and its reliability;Zewditu Hospital;Addis ababa;2009. In: Teclemariam M, Legesse B and Wasie B (eds). ). Extracts from EPHA-sponsored Master`s Theses in HIV/AIDS. Addis Ababa, Ethiopa: Ethiopian Public Health Association (EPHA), extract no 12,2010:36.

[3] Assefa N.Sexual behavior and determinants of condom use among HIV/AIDS patients who are on ART in North Shewa Health facility,2010/2011.Addis ababa,Ethiopia,may,2011.

[4] Regnarsson A, Mila A,Corter J,and et al.Sexual risk taking among patients on ART in an urban informal settlement in Kenya;Cross-sectional survey.Journal of international AIDS society

2011,14:20(http:www,jiasociety.org/content/14/1/20).

[5] Belay E. Asseessement of risky sexual behavior for HIV/AIDS among male daily laborers in Kombolcha Town, North East Ethiopia. In: Legesse B, Seyoum D, and Lakew Y(eds). Extracts from EPHA-sponsored Master`s Theses in HIV/AIDS. Addis Ababa, Ethiopa: Ethiopian Public Health Association(EPHA), extract no 4,2008:68.

[6] Dessie y.Risky sexual practice and factors related among PLWHA attending ART in addis ababa public hospital addis ababa, Ethiopia;2009.
[7] Dessie Y. Risky sexual practice and factors related among people living with HIV/AIDS attending their ART in Addis Ababa Public Hospitalsl. . In:Legesse B , and Tekelemariam $M$ (eds).Extracts from EPHA-sponsored Master`s Theses in HIV/AIDS.Addis Ababa,Ethiopa:Ethiopian Public Health Association(EPHA), extract no 11,2010:11.

[8] Asres B, and yiftu B, risky sexual behavior of hiv patients on antiretroviral therapy in sub-Saharan Africa 2012,9:9-14.

[9] jashuo O, olutosin A,IssacF,Phyllis J, condom use among antriviral therapy patients in Ibaden,Nigeria.2010;4( ):49550.

[10] Feredrick k. knowledge, Attitude, and practice of condom use in a time of highly active antiretroviral therapy(HAART), iin rural area in Uganda;20.

[11] Crumm F, Riffenugh R, Wenger sagan B, Fasker S. Comparssion of causes of disease and mortality rates among HIV infected persons: analysis of the pre, early and late of HAART eras.2006;194-200.

[12] Estifanos Y, Dessalegn T, Solomon M,et al. patterns of condom use and associated factors among adult HIV positive clients, in north western Ethiopia.2012;12(13):5052.

[13] Yedeta D, Mulusew G, Abdo B, risky sexual practice and related factors among antiretroviraltherapy attendees in addis ababa pubic hospitals, Ethiopia.2009.

[14] Debeko K.Sexual and reproductive health needs and preferences of PLWHIV/AIDS. In: Legesse B,Seyoum D, and Lakew Y(eds). Extracts from EPHA-sponsored Master`s Theses in HIV/AIDS. Addis Ababa, Ethiopa: Ethiopian Public Health Association(EPHA),extract no 5,2008:77. 